Erratum

\title{
Erratum: Balconi, M.; et al. Evidences from Rewarding System, FRN and P300 Effect in Internet-Addiction in Young People SHORT TITLE: Rewarding System and EEG in Internet-Addiction Brain Sciences 2017, 7, 81
}

\author{
Michela Balconi ${ }^{1,2, *}$ (D) , Irene Venturella ${ }^{1}$ and Roberta Finocchiaro ${ }^{1}$ \\ 1 Research Unit in Affective and Social Neuroscience, Department of Psychology, Catholic University of the \\ Sacred Heart, 20123 Milan, Italy; irene.venturella@unicatt.it (I.V.); roberta.finocchiaro@unicatt.it (R.F.) \\ 2 Department of Psychology, Catholic University of the Sacred Heart, Milan Largo Gemelli, 1, \\ 20123 Milan, Italy \\ * Correspondence: michela.balconi@unicatt.it; Tel.: +39-2-72342586; Fax: +30-2-72342280
}

Received: 30 August 2017; Accepted: 7 September 2017; Published: 11 September 2017

We would like to submit the following erratum to our recently published paper [1] due to the error in the title. We request to change the title to "Evidences from Rewarding System, FRN and P300 Effect in Internet-Addiction in Young People", and delete "SHORT TITLE: Rewarding System and EEG in Internet-Addiction".

We apologize for any inconvenience caused to our readers.

Conflicts of Interest: The authors declare no conflict of interest.

\section{References}

1. Balconi, M.; Venturella, I.; Finocchiaro, R. Evidences from Rewarding System, FRN and P300 Effect in Internet-Addiction in Young People SHORT TITLE: Rewarding System and EEG in Internet-Addiction. Brain Sci. 2017, 7, 81. [CrossRef] [PubMed]

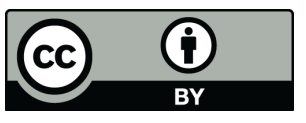

(C) 2017 by the authors. Licensee MDPI, Basel, Switzerland. This article is an open access article distributed under the terms and conditions of the Creative Commons Attribution (CC BY) license (http://creativecommons.org/licenses/by/4.0/). 